\title{
Quality assurance in revision total hip arthroplasty
}

\author{
Christos Koutras $^{\mathrm{a}, *}$, Isabel Becker ${ }^{\mathrm{b}}$, Stavros A. Antoniou ${ }^{\mathrm{c}}$, Hansjoerg Heep ${ }^{\mathrm{d}, \mathrm{b}}$ \\ ${ }^{a}$ Klinikum Arnsberg, Clinic for Orthopaedics, Nordring 37-41, 59821, Arnsberg, Germany \\ b University Duisburg-Essen, Hufelandstraße 55, 45147, Essen, Germany \\ c 401 General Military Hospital of Athens, Kanellopoulou 6, 11527, Athens, Greece \\ d Helios Klinikum Niederberg, Clinic for Orthopaedics, Robert-Koch-Straße 2, 42549, Velbert, Germany
}

\section{A R T I C L E I N F O}

\section{Keywords:}

Arthroplasty

Data collection

Health care

Hip replacement

Quality assurance

\begin{abstract}
A B S T R A C T
Objective: To compare two different methods of clinical outcomes prospective documentation after revision hip arthroplasty: external and internal.

Methods: Chi-squared test, Fisher's exact test and binary logistic regression analyses were performed.

Results: Eighty one patients experienced a complication (520 arthroplasties). A significant difference was found between the two documentation methods in the variable "hematoma and postoperative hemorrhage", and a significant reduction of the internally and externally documented "total complication rate". Furthermore, the „length of hospital stay" and "duration of operation" predicted independently the occurrence of complications. Conclusion: Further improvement of documentation methods is required to measure the perioperative morbidity.
\end{abstract}

\section{Introduction}

Quality assurance (QA) aims to analyze processes and outcomes in order to develop and improve patients' healthcare. It focuses on the provision of confidence that the quality requirements in healthcare delivery are met. ${ }^{1}$ QA may be internal (institutional) or external (database). The objective of internal QA is to document the outcomes in the context of self-monitoring, identify shortcomings in the provision of healthcare and encourage the implementation of corrective measures. External QA is particularly valuable in the hospital benchmarking process and the evaluation of the provision of healthcare in national or international level.

There are no studies comparing the external and internal documentation methods for revision hip arthroplasty procedures. Primary aim of the present study was to compare the external and internal documentation after revision total hip arthroplasty. Secondary aim was to evaluate the incidence of postoperative complications across the study period and to investigate a possible association with gender, duration of operation, duration of hospital stay and age.

\section{Methods}

Data of patients subjected to revision hip arthroplasty in the Orthopedic Department of the university-affiliated Hospital Essen-
Werden between 2004 and 2014 were prospectively collected from internal and external documentation databases. Institutional review board approval was obtained for this study.

External documentation was performed through an electronic form according to Part V of the German Social Security Code. ${ }^{2}$ Electronic submission of the quality assurance data in Germany are required to be submitted yearly. Incomplete forms are not allowed to be submitted. The documentation was completed in our department by the attending surgeon of each patient within 4 weeks from the date of discharge. The records were maintained and evaluated by the Federal Office for Quality Assurance (BQS) ${ }^{3}$ from 2001 to 2008 and by the AQUA-Institute $^{4}$ from 2009 to 2014. Data from the hospitals in North RhineWestphalia are first collected by the office quality assurance NRW (qsnrw). ${ }^{5}$ This external quality assurance documentation was launched and implemented in our Department since 2001.

The internal documentation was conducted with pen and paper by physicians on the day of discharge. The records have been kept in our Department and were thoroughly scrutinized in the case of suspected increase in complication rates. Both documentation form templates are available upon request.

The Pearson's chi-squared test or the Fisher's exact test was performed to compare internal with external data and the incidence of complications observed during the five-year periods 2005-2009 and 2010-2014. The Mann-Whitney $U$ test was used to compare continuous

\footnotetext{
* Corresponding author.

E-mail addresses: christos.koutras@gmail.com (C. Koutras), isacer@web.de (I. Becker), stavros.antoniou@hotmail.com (S.A. Antoniou), hansjoerg.heep@uk-essen.de (H. Heep).
} 
outcomes in the two periods. Binary logistic regression analyses were performed in SPSS 22.0 (SPSS Inc., Chicago, Illinois, USA) with the event of complication as dependent variable and gender, normalized duration of operation, normalized length of hospital stay and normalized patient age as independent variables. The transformation of continuous variables to normal was conducted through a two-step process in SPSS described by Templeton, ${ }^{6}$ as indicated according to Kolmogorov-Smirnov test. Statistical significance was set at a p-value of 0.05 for all tests.

\section{Results}

The total number of revision hip arthroplasties was 520. The median age of patients who have experienced a complication was 76 years (range: $38-91$ ) and $27.2 \%$ were male. The number of patients having experienced at least one postoperative complication was 52 and 63, documented in the internal and external databases, respectively (after exclusion of patients with postoperatively ambiguously defined changes in mobility). The median postoperative length of stay of patients having experienced a complication was 21 days (range: $0-101$ ) and the median duration of operation was $166 \mathrm{~min}$ (range: 60-483).

Complication events observed in our internal and external quality assurance datasets are presented in the bar chart of Fig. 1. The most frequent complications were reintervention (18.5\%, external data), fracture $(14.8 \%$, external data) and cardiovascular complications (13.6\%, internal data). A statistically significant difference between the internal and external datasets was detected in the "inability to walk at discharge" ( $p=0.0004)$.

A statistically significant reduction of the complication rate was observed during the second period of observation (2010-2014) according to the internally ( $\mathrm{p}<0.0001$, OR 5.5 and CI 2.6-11.6) and externally ( $\mathrm{p}=0.02$, OR 2.1 and CI 1.2-3.6) documented "total complication rate". The absolute numbers of complications in the two study periods are presented in Table 1 . The median of length of hospital stay for the time periods 2005-2009 and 2010-2014 were 19 and 23 days, respectively. This difference was non-significant according to MannWhitney $U$ test ( $p>0.05$ ).

Furthermore, binary logistic regression analysis after removal of insignificant independent variables demonstrated that the variable „normalized length of hospital stay” independently predicted the occurrence of several complications, including reintervention (internal), complications (internal) and wound healing disorders. The variable "duration of operation" was associated with the occurrence of a reintervention (external). Table 2 shows the results of the binary logistic regression analyses. Post hoc binary logistic regression analyses with ASA score as independent binary variable (ASA-score 1-2 or ASA-score 3-4) suggested that ASA score was not associated with the occurrence of complications.

\section{Discussion}

The main finding of this study is a substantial difference between internal and external documentation in a key parameter of quality assurance, namely the "inability to walk at discharge" $(\mathrm{p}=0.0004)$. A significant reduction of the complication rate was observed during the period 2010-2014 in both datasets. Furthermore, the incidences of hematoma and postoperative hemorrhage were significantly different in the two time periods. Finally, the length of hospital stay and the duration of operation were independent factors predicting the risk of complications, suggesting increased risk of postoperative morbidity in patients subjected to total hip arthroplasty.

The reduction of complication rates (2010-2014) may be due to the

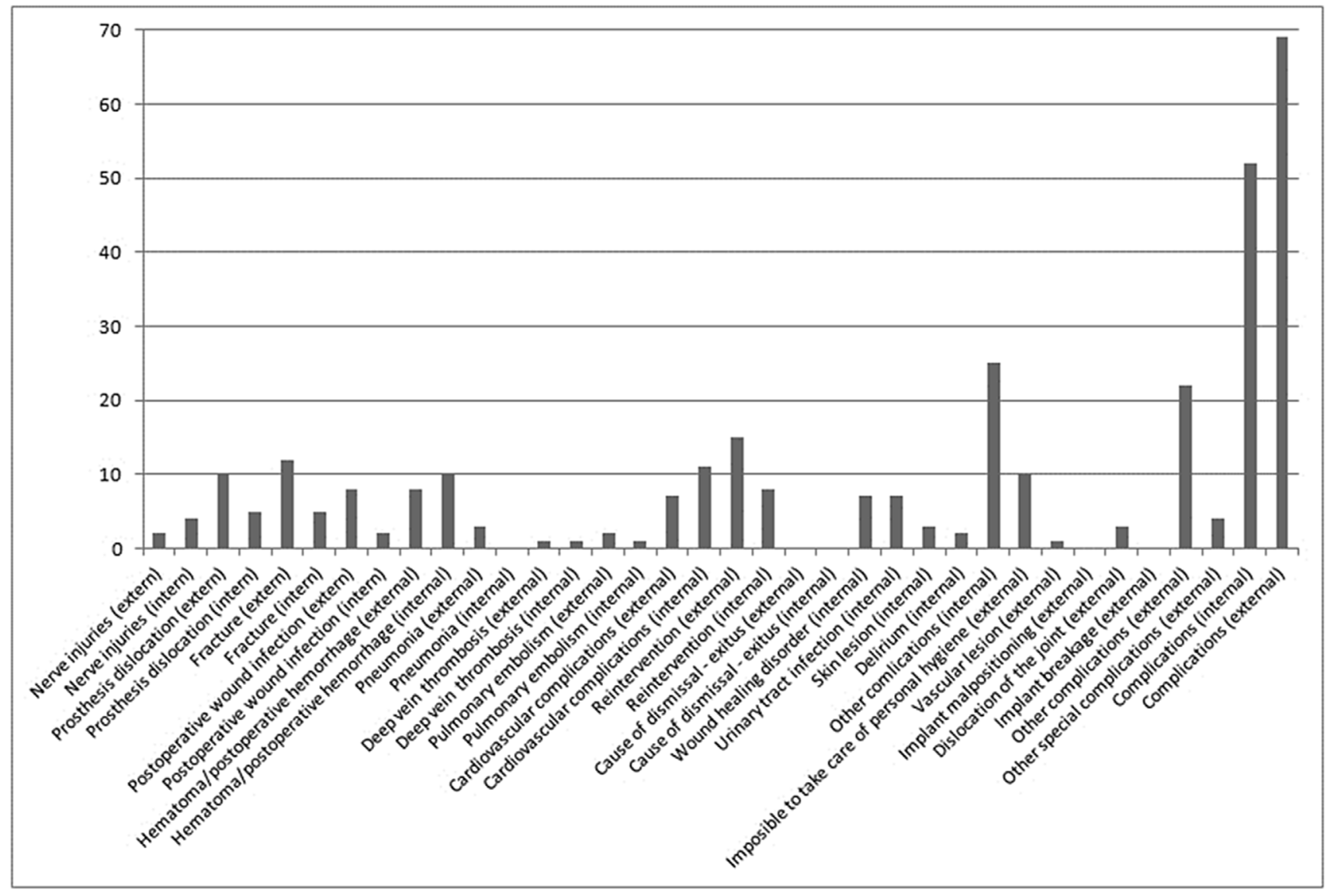

Fig. 1. Number of patients with internally or externally documented complications. 


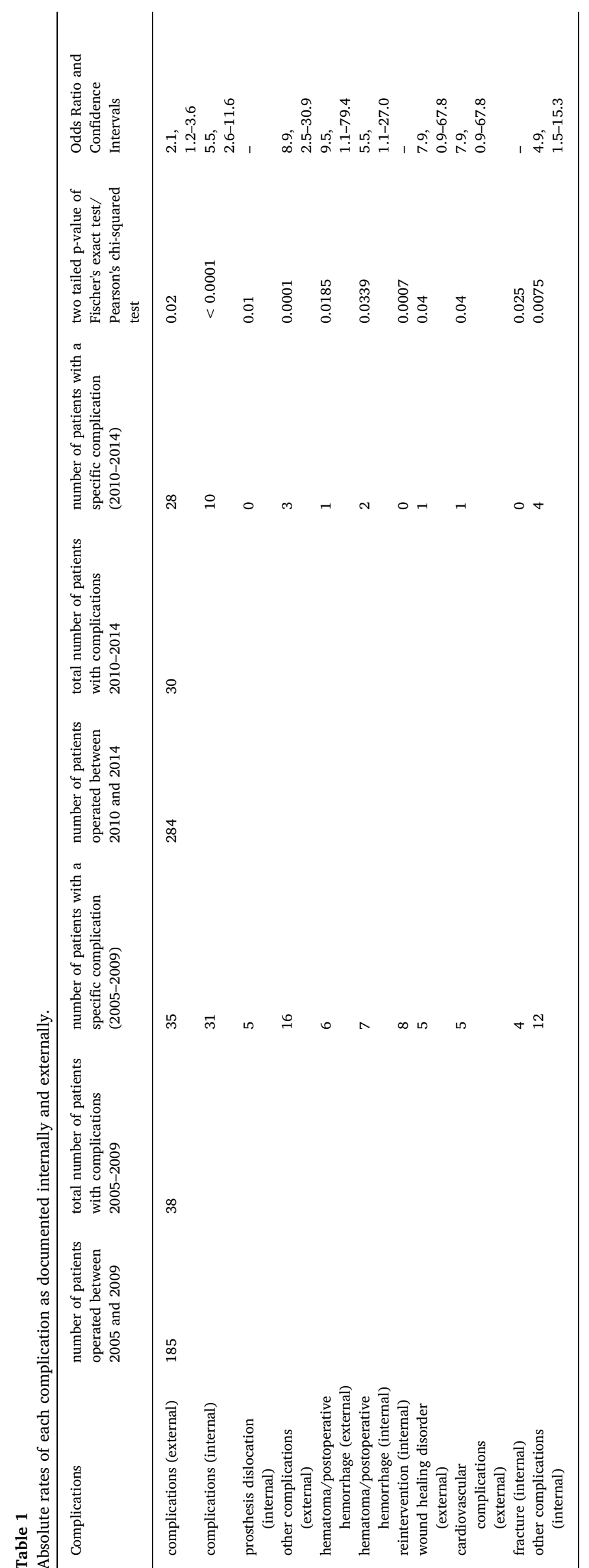

Table 2

Significant results of binary logistic regression analyses.

\begin{tabular}{|c|c|c|c|}
\hline Dependent Variable & $\begin{array}{l}\text { Independent } \\
\text { Variable }\end{array}$ & Sig. $(\mathrm{p}<0.05)$ & Exp.(B) \\
\hline internal complications & NormLOS & $<0.001$ & 1.111 \\
\hline external fracture & NormSD & 0.014 & 1.035 \\
\hline internal fracture & NormSD & 0.026 & 1.036 \\
\hline $\begin{array}{l}\text { internal hematoma/ } \\
\text { hemorrhage }\end{array}$ & NormLOS & 0.016 & 1.096 \\
\hline internal reintervention & NormLOS & $<0.001$ & 1.192 \\
\hline $\begin{array}{l}\text { internal wound healing } \\
\text { disorders }\end{array}$ & NormLOS & $<0.001$ & 1.392 \\
\hline internal urinary tract infection & NormSD & 0.034 & 0.979 \\
\hline internal other complications & NormSD & 0.005 & 1.014 \\
\hline
\end{tabular}

Dependent variable: occurrence of complication.

Independent variables: gender, normalized duration of operation, normalized length of hospital stay and normalized patient age).

Abbreviations: NormAge - normalized age, NormLOS - normalized length of hospital stay, NormSD - normalized duration of operation.

surgical experience accumulated in revision arthroplasties, the low turnover of senior physicians in our department and the standardization of practice and adaptation of improved clinical guidelines. The "inability to walk at discharge" demonstrated a statistically significant difference between the internal and the external datasets, probably due to a more sensitive judgment of the lack of ability to walk using the external documentation method. The length of hospital stay (19 vs. 23 days) was not reduced through time, as expected. Potential reasons for the lack of reduction in the length of hospital stay may be the expected limited number of revision operations per year (limited surgical experience) and the worse patients' general health, which made a further reduction of length of stay difficult.

We could not identify an association between gender and the incidence of complications. Similarly, no association between ASA-score classification and complication rates was observed. Taking into account that the median of length of hospital stay was 21 days through the study period, we may assume that, in the case of revision total hip arthroplasty, a large part of complications, such as venous thromboembolic events has been captured in the present study. A recent study ${ }^{7}$ described that the median time of venous thromboembolism was eleven days after hip arthroplasty. Furthermore, flawed data may act as confounders in multivariate analysis. In a recent work, ${ }^{8}$ the documented complications for the external quality assurance may be over- (up to $20 \%$ ) or underdocumented (up to $-30 \%$ ). Finally, postoperative hemorrhage was among the most frequent complications in the present study. Two of the main reasons could be that the revision total hip arthroplasty operations are complicated procedures and they have been associated with longer operative duration. Postoperative hemorrhage was also the most frequent complication in a quality assurance study of patients with femoral neck fractures in Germany. ${ }^{9}$

Several publications investigated the role of patient characteristics on the morbidity after total hip or total joint replacement. Young age and male gender, older age and female gender, ${ }^{10}$ high ASA score, ${ }^{11}$ obesity, ${ }^{12,13}$ young age ${ }^{12}$ and diabetes ${ }^{12,13}$ have been identified as risk factor for the occurrence of complications. Greater mortality rate has been described in total joint replacement patients with higher ASA score ${ }^{11}$ and higher rate of complications. ${ }^{14}$ The incidence of death after major joint arthroplasty is rare. ${ }^{15}$ This fact makes morbidity a more suitable control measure, in contrast to mortality.

The present study findings may be generalized to departments performing 300-600 total joint arthroplasties per year. Comorbidities were not documented in the present study, precluding further exploration of their relevance to the complication rate. Furthermore, the definition of complications using the internal and external documentation paths was different, making a direct comparison difficult. The continuous parameters were normalized through a two-step 
process ${ }^{6}$ making a data back-transformation not possible. Finally, a medical chart review, which would allow assessment of both documentation methods against a gold standard, was not conducted due to limited resources.

\section{Conclusion}

The documentation processes of revision total hip arthroplasties should be improved in a more efficient way. Possible factors associated with the reduction of the incidence of complications through time may be the surgical experience in revision hip arthroplasties, the low turnover of senior physicians, the improved implementation of clinical guidelines and the impact of continuous monitoring of complications through internal and external quality assurance.

\section{Funding}

This research did not receive any specific grant from funding agencies in the public, commercial, or not-for-profit sectors.

\section{References}

1. ISO, E. Quality management systems. Fundamentals and vocabulary (ISO 9000: 2015). Sozialgesetzbuch (SGB) Fünftes Buch (V). Available at:. https://www.gesetzeim-internet.de/sgb_5/index.html, Accessed date: 15 May 2017.

2. Sozialgesetzbuch (SGB) Fünftes Buch (V). Available at: https://www.gesetze-iminternet.de/sgb 5/index.html, Accessed date: 15 May 2017.

3. BQS - Bundesgeschäftsstelle Qualitätssicherung. Available at: https://www.bqs.de/, Accessed date: 21 April 2017.

4. AQUA - Institut für angewandte Qualitätsförderung und Forschung im

Gesundheitswesen. Sektorenübergreifende Qualitätssicherung. Available at: https:// www.aqua-institut.de/de/projekte/137a-sgb-v/, Accessed date: 22 January 2017.

5. qs-nrw - Qualitätssicherung Nordrhein-Westfalen. Available at: https://www.qs-nrw. org/. Accessed April 21, 2017.

6. Templeton GF. A two-step approach for transforming continuous variables to normal: implications and recommendations for IS research. Commun Assoc Inf Syst. 2011;28(4):41-58.

7. Kester BS, Merkow RP, Ju MH, et al. Effect of post-discharge venous thromboembolism on hospital quality comparisons following hip and knee arthroplasty. $J$ Bone Joint Surg Am. 2014;96(17):1476-1484.

8. Jakob J, Marenda D, Sold M, Schlüter M, Post S, Kienle P. Quality of documentation of intraoperative and postoperative complications: improvement of documentation for a nationwide quality assurance program and comparison with routine data. Chirurg. 2014;85(8):705-710.

9. Smektala R, Schulze-Raestrup U, Müller-Mai C, Siebert H. More patients in a shorter inpatient stay with better outcome in treatment of femoral neck fracture: external quality assurance in Westfalia-Lippe on 50,354 patients. Unfallchirurg. 2014;117(11):1012-1023.

10. Santaguida PL, Hawker GA, Hudak PL, et al. Patient characteristics affecting the prognosis of total hip and knee joint arthroplasty: a systematic review. Can J Surg. 2008;51(6):428-436

11. Hooper GJ, Rothwell AG, Hooper NM, Frampton C. The relationship between the American Society of Anesthesiologists physical rating and outcome following total hip and knee arthroplasty: an analysis of the New Zealand Joint Registry. $J$ Bone Joint Surg Am. 2012;94(12):1065-1070.

12. Malinzak RA, Ritter MA, Berend ME, et al. Morbidly obese, diabetic, younger, and unilateral joint arthroplasty patients have elevated total joint arthroplasty infection rates. J Arthroplasty. 2009;24(6 Suppl):84-88.

13. Jämsen E, Nevalainen P, Eskelinen A, Huotari K, Kalliovalkama J, Moilanen T. Obesity, diabetes, and preoperative hyperglycemia as predictors of periprosthetic joint infection: a single-center analysis of 7181 primary hip and knee replacements for osteoarthritis. J Bone Joint Surg Am. 2012;94(14) e101.

14. Rauh MA, Krackow KA. In-hospital deaths following elective total joint arthroplasty. Orthopedics. 2004;27(4):407-411

15. Romano PS, Schembri ME, Rainwater JA. Can administrative data be used to ascertain clinically significant postoperative complications? Am J Med Qual. 2002;17(4):145-154. 